\title{
EL ESPAÑOL EN LA SUIZA ALEMANA: CARACTERÍSTICAS LÉXICAS DE LA SEGUNDA GENERACIÓN DE HISPANOHABLANTES
}

\author{
FÉLIX JIMÉNEZ RAMÍREZ \\ (Universidad de Zúrich)
}

\begin{abstract}
The linguistic situation of the second generation of Spaniards in theGermanspeaking part of Switzerland is the result of the contact of different languages and multilingualism. Their Spanish is determined by German, Swiss-German, Italian and even French influences. The reason for their desviation from standard Spanish lies in the fact, that their scholar education is in the local language and that they only Icarn and usc spoken Spanish at home. The desviation from standard Spanish is not to be interpreted as symptoms of language attrition, but as the result of their linguistic competence in various languages. This paper presents and analyses the Iexical characteristic of the second generation of Spanish-speaking people in the German-speaking part of Switzerland.
\end{abstract}

\section{Presentación}

La situación lingüística de la Suiza alemana presenta una complejidad tal, que destaca de manera especial como un campo de estudio apasionante para el lingüista. La realidad de este pequeño país que cuenta con cuatro lenguas nacionales se complica cuando añadimos la presencia de otros idiomas que han venido con los trabajadores extranjeros instalados en su territorio desde los años 50 . Suiza se ha convertido en la actualidad en país multilingüe, donde la confïguración tradicional de sus idiomas está en proceso continuo de transformación por la existencia de importantes minorías en cada área lingüística y el proceso de globalización económica.

El italiano como lengua franca entre trabajadores extranjeros, en especial dentro de la zona lingüística alemana, ha merecido una gran atención por parte de los 
investigadores (Berruto, 1984 y 1991; Franceschini/Müller/Schmid 1984; y Schmid, 1986 y 1994).

En cuanto al español, el estudio de las condiciones en que se desenvuelve la segunda generación de españoles en Suiza fue abordado en un encuentro celebrado en Zúrich en 1982, del cual se publicaron las memorias (López de Abiada/López Bernasocchi, 1982); y en los últimos años por un equipo de investigación dirigido por Georges Lüdi, de la Universidad de Basilea, centrado en la Suiza de habla francesa. Con este trabajo queremos contribuir a aportar más luz sobre el estado del contacto del español traído por los emigrantes a la Suiza alemana.

La situación que presentamos no es nueva en la historia del español. El contacto con otras lenguas ha sido una constante en la expansión de la lengua española: En la actualidad, la situación con el inglés, principalmente en Estados Unidos, se acerca bastante al panorama que encontramos en Suiza, es decir, lengua de emigración en un país donde la cultura dominante presiona y dificulta el mantenimiento de la lengua, pero a la vez, a partir de la segunda generación, favorece la mezcla y el desarrollo de nuevas formas de supervivencia diferentes a la original (cf. Silva-Corvalán, 1992). La diferencia fundamental reside en que el aporte de hispanohablantes se mantiene constante en los Estados Unidos, mientras que en Suiza sucede lo contrario, el retorno a España de quienes alcanzan la edad de jubilación conduce a una disminución del número total de españoles. En 1997 residían en Suiza 94.898 españoles, es decir el 6,9\% de los extranjeros (1.375.158, el $19,4 \%$ de la población total del país), según la Oficina Federal de Estadística de Suiza.

Si echamos una mirada atrás encontraremos que ya una vez una variedad de español siguió una evolución propia y distinta a la estándar al ser separada del tronco común e influida por el contacto con otras lenguas: se trata del judeoespañol. Con toda probabilidad una de las causas de que sobreviviera durante quinientos años fue la evolución de su propio sistema que aceptaba la adquisición de elementos de otras lenguas, pero siempre manteniendo la estructura original hispana (Bossong, 1987; Sala, 1998: 39). Por supuesto también en el judeoespañol la mezcla lingǘstica ha sido considerada como un elemento de influencia negativa, como denuncia al respecto Bossong:

Das gesprochene Judenspanisch der Balkanländer und des Vorderen Orients gilt, nach Meinung Aussenstehender Beobachter ebenso wie vieler Sprecher, als Prototyp einer Mischsprache. Im allgemeinen wird diese Charakteristik als ein Stigma angesehen, und zwar nicht nur wegen der negativen Assoziationen, die generell mit dem Begriff der Sprachmischung verbunden sind; es gibt darüber hinaus eine weit verbreitete Auffassung, wonach die extensive Übernahme fremder Elemente ursächlich sei für den Untergang der Sprache. (1987: 1). 
De la misma forma la adquisición de elementos de otras lenguas en las que normalmente se desenvuelven los hispanohablantes en Suiza viene a suplir las posibles deficiencias de comunicación en la lengua materna. Visto desde fuera, con la perspectiva del monolingüe y aplicando de manera estricta la norma del español, puede parecer una tara la invasión de piezas extrañas en el discurso de estos multilinguies; pero desde la perspectiva del bilingüismo el manejo de más de un sistema lingüístico también posee muchas ventajas evidentes, e incluso según algunas investigaciones, los rasgos más chocantes para el monolingüe están siendo explicados de una manera positiva y enriquecedora:

Algunos rasgos del habla bilingüe, como la mezcla lingüística y el «codeswitching», según las investigaciones más recientes, han mostrado ser susceptibles de una nueva interpretación: se puede pensar que son atributos del bilingüe con valor pragmático, y que reflejan su versatilidad e inventiva lingüística; ya no se los tacha de fenómenos de interferencia, que es como hasta hace poco se consideraban todos los ejemplos que se percibían de la influencia de un idioma en el otro. (Hoffmann, 1989: 39).

Hemos de tener presente en todo momento dónde se desarrolla la práctica lingüística de estos hablantes: esencialmente en casa; $y$, por otra parte, con quién: con hablantes que poseen sus mismas características lingüísticas. Por tanto su sistema puede funcionar perfectamente con elementos transferidos de otros idiomas porque es la forma de hacer productiva su lengua como instrumento de comunicación.

La competencia de los hispanohablantes en lengua vernácula está muy determinada por dos grandes aspectos: la educación y la calidad y cantidad de la práctica lingüística:

Mi español es todavía el que traigo de España y no he aprendido más sino que me he olvidado de la lengua española + hablando + y el vocabulario ¿cómo se dice wortschatz? ++ vocabulario + tengo un vocabulario muy exte $=$ reducido + pobre + sí por falta de comunicación y también por falta de escuela ¿no?. (Informante I0)'.

En estas páginas se intentarán exponer las estrategias de producción léxica cuyo resultado se aparta de la norma estándar del español. Los materiales objeto de estudio proceden de encuestas con 24 informantes seleccionados de manera aleatoria. Trece son estudiantes de romanística de la Universidad de Zúrich, los once restantes amigos y conocidos del investigador. Están representadas las diferentes posiciones socioculturales. Todos tienen en común ser hijos de hispanohablantes, haber nacido en Suiza o haber llegado a ese país a temprana edad

\footnotetext{
t + indica pausa; $=$ interrupción de una palabra; $x x x$ ininteligible. Tomados de Schmid, 1994.
} 
acompañando a sus padres. Quince son mujeres y nueve hombres. Sus edades están comprendidas entre los veintiún años del más joven y los treinta y ocho del mayor de los informantes.

El corpus está constituido por entrevistas en forma dialogada (material oral) de unas catorce horas de grabación, y trabajos universitarios, exámenes, mensajes o textos escritos ex proleso para esta investigación (material escrito). Se presenta este trabajo como resultado parcial de la tesis doctoral sobre la situación de contacto del español en la Suiza alemana.

\section{Transferencias}

Como hemos apuntado más arriba, el concepto de interferencia ha sido sustituido en los últimos años por el de transferencia:

Este concepto inicial de «interferencia», basado en el «desvío» de la norma, ha ido dejando paso a otros puntos de vista menos negativos. En intentos sucesivos de matizar el concepto adecuadamente se ha sustituido «interferencia» por «transferencia», dándole a este último término el significado de adopción que hace una lengua de elementos de otra lengua. De esta manera, los elementos nuevos se enfocan positivamente como elementos «adoptados», no como elementos «periurbadores», valor este último que está de alguna manera implícito en el término «interferencias». (Vaquero, 1990: 277).

Sin embargo, se mantiene el concepto de interferencia para aquellos hechos que afectan al sistema en vez de al habla (parole):

Los fenómenos de interferencia consisten en la introducción de elementos extranjeros en los dominios mejor estructurados del idioma - fonología, morfología, sintaxis y en algunas zonas del vocabulario; por ejemplo, las relaciones de parentesco, los colores, el tiempo- e implican una reorganización de las oposiciones más antiguas del sistema en cuestión. (Sala, 1998: 34).

La influencia del alemán, italiano o francés sobre el español en Suiza se puede presentar de diversas formas: Transferencias de elementos léxicos, es decir palabras tomadas directamente como préstamo; transferencia de frases con valor pragmático para cambiar el estilo o hacer incisos en el discurso, lo que llamamos cambio de código; la adaptación de los términos de la otra lengua a la morfología y fonética del español, a veces con reajuste semántico; transferencia semántica por medio de calcos semánticos; y por último, puede transferir criterios a la hora de seleccionar cl vocabulario, es decir la preferencia por determinados términos y el rechazo de otros por influencia de las lenguas en contacto. 


\section{I. Elementos léxicos}

El contacto de lenguas favorece el trasvase de elementos léxicos. De esta manera, una característica muy evidente de la producción lingüística en el español de los hispanohablantes de Suiza es la adopción de voces de las lenguas que entran en contacto. Este fenómeno ha sido denominado con frecuencia como mezcla lingüístical.

Cada hablante toma según el momento o la memoria, los elementos que necesila y que no posec o no recuerda, o que son más efectivos en relación con la realidad a la que se desea referir. Existe entre los encuestados una plena consciencia de estar mezclando los sistemas para alcanzar sus necesidades comunicativas, aunque esto suceda de una manera más o menos automática e irreflexiva, tal como explica uno de los informantes:

«Nosotros ++ nuestro habla es muy especial porque nosotros ++ nosotros lo mezclamos con el [alemán/suizo ++ a lo mejor me salta +++ tres o cuatro palabras en español y lucgo lo otro en [alemán]suizo, lo mezclamos todo así que no ++ y no nos damos ni cuenta, que de pronto hablamos en [alemán]suizo o el italiano mismo». (Inf: 12).

En el matcrial rccogido se encuentra toda una serie de elementos léxicos tomados como préstamo. Se trata de voces pertenecientes a diferentes campos semánticos que se prefieren en un momento determinado a las correspondientes españolas por diversas razones. Las voces proceden no sólo de la lengua dominante cn el territorio, alcmán en este caso, sino que es posible encontrar también términos originarios de otros idiomas que por diferentes motivos adquieren relevancia para cstos hablantes.

En los materiales recogidos se encuentran los siguientes elementos léxicos de origen alemán. Están tomados como palabras alemanas incrustadas en el discurso en español. Algunos han sido agrupados en campos semánticos, otros, en cambio, no guardan relación directa con los demás préstamos:

-Educación

- Bucno hice el kindergarten aquí + luego hice la secundaria + y hice un aprendizaje como dibujante ++ delineante se dice $¿$ no? (Inf. 15, oral).

- Educación elementar. (Inf. 1, escrito).

- Hice hasta el segundo año la escuela normal + después tuve que hacer hilfssclute por el motivo también porque cambia= cambiaba las palabras o así. (Inf. 18, oral). 
- Hice + después los tres años últimos que son dreiwerkschuljahre que se llaman aquí. (Inf. 18, oral).

- Yo terminé la matura con 18 + era agosto. (Inf. 13, oral).

- Primero quiero acabar con el lizenziat. (Inf. 17, oral).

- Eso sí que no sé decirlo en español schulpädagogin, kinderpädagogin ++ pedagogo de niños me ha aconsejado de hablar yo un idioma mi marido otro idioma hasta los tres años. (Inf. 23, oral).

- Después de la realschule he hecho un aprendizaje + maschinenmekaniker ¿qué es en español + mecánico de maquinaria me parece? + cuatro años [...] luego hice una escuela handelschule + ¿cómo se dice? (Inf.24, oral).

Se puede observar la presencia numerosa de voces del mundo de la educación a causa de su relación directa con la realidad suiza, característica ya señalada por otros investigadores como Franceschini/Müller/Schmid (1984: 62-63) para italianos cn Suiza, o Vilar (1995: 334) para españoles en Alemania. En el caso de ELEMENTAR en lugar de ELEMENTAL, la coincidencia fonética favorece la escritura de la forma alemana. Además el informante es de origen andaluz y en esta variedad de español [-1] y [-r] en posición final se suelen neutralizar con frecuencia.

-Trabajo y administración

- Como mi padre era saisonnier + pues hasta los ++ de cinco años hasta los ocho teníamos que siempre volver a España + siempre. (Inf. 12, oral).

- El centro no tenía unos fondos como + para disponer para darle el encargo a una + a una firma aquí. (Inf. 11, oral).

- Aquí se están poniendo las cosas peor que en España, por el trabajo + no sé antes por ejemplo + ahora piden más para pagar el steuer y se gana muy poco, se gana muy poco para lo que tenemos que pagar. (Inf. 12, oral).

- Es para una oficina que hace comunication management + no sé cómo se llama en español y entre otras cosas también hacen ++ medienanalyse tampoco sé cómo se dice en español. (Inf. 7, oral).

- Después de la realschule he hecho un aprendizaje + maschinenmekaniker ¿qué es en español + mecánico de maquinaria me parece? + cuatro años. (Inf. 24, oral).

Los términos laborales hacen referencia a realidades fundamentales como son, por una parte, la estacionalidad del trabajo que supone un tipo específico de permiso de residencia y de situación laboral. SAISONIER es, por tanto, un término relevante en el léxico de estos informantes cuyo uso y frecuencia está ligado a la vida en Suiza.

Por otra parte, el término EMPRESA, se sustituye por la denominación alemana e italiana FIRMA - en los últimos tiempos se ha introducido este término en español, especialmente en el lenguaje de los negocios y el periodismo de asuntos 
económicos- El empleo frecuente, su constitución fonética y la homografía con una palabra española favorecen su uso.

Para MEDIENANALYSE y MASCHINENMECHANIKER la explicación consiste en que los informantes desconocen el nombre de estas labores en español y con el objeto de coseguir una mayor efectividad en la comprensión del mensaje prefieren usar el término original, para a continuación intentar su traducción. En general existe una tendencia a nombrar las instancias y procedimientos administrativos con su denominación original, lo que explicaría tanto los términos laborales antes presentados como la aparición de STEUER.

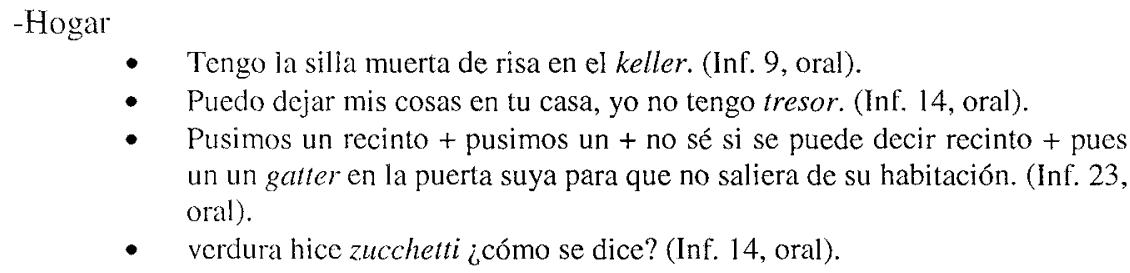

- Tengo la silla muerta de risa en el keller. (Inf. 9, oral).

- Puedo dejar mis cosas en tu casa, yo no tengo tresor. (Inf. 14, oral).

- Pusimos un recinto + pusimos un + no sé si se puede decir recinto + pues un un gatter en la puerta suya para que no saliera de su habitación. (Inf. 23, oral).

- verdura hice zucchetti ¿cómo se dice? (Inf. 14, oral).

Especial atención merece la palabra KELLER 'sótano' por tratarse de un término que en la sociedad suiza tiene una relevancia mucho mayor que en España y de ahí un uso cotidiano muy frecuente. Esto se debe a cuestiones de hábitat, es decir, cn la mayor parte de los apartamentos suizos el sótano cumple una función dc almacén, bodega y guardarropa muy importante de la que carece en España, por ejemplo. En el español de los Estados Unidos el campo léxico de la casa es uno de los que presenta mayor número de préstamos (Ramírez, 1992: 197). El caso de GATTER 'puerta de una verja o cercado', en el contexto que nos ocupa 'barrera que se coloca en la puerta de las habitaciones para impedir el paso de un niño' lo intenta explicar el informante basándose en el significado de 'cercado' pero finalmente opta por usar la palabra alemana para asegurar la comprensión.

-Geografía

- Seychelles, las islas del océano Pací= + Índi= + Indischer Ozean. (Inf. 11, oral).

- Pero después pienso por el dinero que ya me he gastado podía haber ido al Karibik y otra vez para casa. (Inf. 18, oral).

Los términos geográficos se suelen aprender en el periodo educativo, el dcsconocimiento o el olvido de estas voces en español se debe a su adquisición en alemán y la mayor frecuencia de uso en esta lengua.

Uno de los informantes que juega al fútbol en un club de aficionados, conoce la denominación de las competiciones y de las posiciones de los jugadores en el 
terreno de jucgo sólo en alemán, si bien durante la entrevista intenta la traducción al cspañol:

- Empecé en lo de más abajo quinta + fiunfle liga. (Inf. 12, oral).

- Mittelfeld icentrocampo? (Inf. 12, oral).

El resio de los ejemplos son casos aislados que también podríamos encontrar en otros informantes.

A veces, estos hablantes se deciden de manera inconsciente por un término que conocen y dominan mejor, pero pensando que aquél coincide en las dos lenguas, como en el caso de BASIS en vez BASE:

- El latín puede ser considerado, pues, la basis de la lengua hispánica. (Inl. 1, escrito).

- Sobre la relación del signo semántico como basis para la investigación semántica de la estructura. (Inf. 2, escrito).

También puede ocurrir que simplemente se desconozca la palabra española y la solución adoptada consista en añadir entrecomillada la correspondiente en alemán, as FÖRDERN sustituye a FAVORECER, PROMOVER, FOMENTAR. El verbo alemán, en nuestra opinión, es más frecuente en la lengua coloquial que sus correspondientes españoles:

- Intención de todas las regiones bilingües de «fördern» su propia lengua. (Inf. 5, escrito).

El recurso a la transferencia abarca a expresiones habituales en la actividad del hablantc, el sustantivo HINTERGRUND 'trasfondo' se presenta en alemán porque se trata de la fórmula que el informante usa para referirse a este concepto. El desconocimiento de la forma española es también muy probable:

- $Y$ me gustan mucho las [biografías] que tienen un poco de xxx hintergrund histórico. (Inf. 1, oral).

Este desconocimiento abarca en especial a expresiones de carácter coloquial, VITAMIN B en el sentido de 'enchufe' que se presenta como la fórmula empleada habitualmente:

- A los hijos [de los] que le convenían sólo les daba las notas buenas + vitamin $B$ como decimos aquí. (Inf. 23, oral).

El cambio al alemán se puede deber también a la necesidad de enfatizar: 
- Me cncantaría dar ciases de español + me encanta + gente mayor + erwacisene $++y$ adultos bueno. (Inf. 13, oral).

Otra scric de términos habituales en alemán, pero procedentes del inglés, se manifiesta cn cl uso lingǘstico de estos hablantes: Del mundo de la informática los informantes usan COMPUTER, HARDDISC; relativo al deporte y al ocio es frecuente hablar de ROLLERBLADE 'patines'; de la terminología laboral COMUNICATION MANAGEMENT y PROPOSAL 'propuesta'; y por último la cxpresión COOL 'chachi, guay' propia del lenguaje juvenil y coloquial. Todos estos términos corrientes en alemán se usan como si también lo fueran en español, muy probablemente por la consciencia que tienen muchos hablantes de ser términos de amplia difusión internacional.

La influencia del italiano se aprecia de forma especial en el léxico de dctcrminados inlormantes. Una gran parte de los hispanohablantes ha recibido una influencia directa del italiano al ser éste una lengua franca entre grupos de trabajadores cxtranjeros (Schmid, 1994).

La alternancia de los términos italianos y españoles en un mismo informante y una misma entrevista no es extraña. Unos ejemplos: CAMPESINOS y CONTADINOS:

- No hay + no creo que haiga tantos campesinos + antes había más fábricas pcro han cerrado bastante [...] pero contadinos no creo que haya muchos ++ no hay muchos alrededor sí. (Inf. 1, oral).

CASI y QUASI:

- Una icngua es «Abstandsprache» cuando por tan grande distancia [...] no se puede entender casi nada. [...] Ausbausprache es una lengua que por claboración $[\ldots]$ es distinta de la lengua que anteriormente fue quasi igual que ella. (Inf. 22, cscrito).

Las orras transferencias se producen en campos semánticos diversos. La mayoría de los adelantos técnicos en el campo de los electrodomésticos que se han producido en los últimos decenios ha estado al alcance de los emigrantes españoles de là primera gencración una vez instalados en Suiza. Por esta razón la denominación más común entre ellos es la italiana, o a veces la alemana. Las ocurrencias que aquí se presentan no son más que algunas de las múltiples que se pueden escuchar entre los españoles en Suiza.

- Lucgo cac clla en una videocaseta que allí todo real. (Inf. 12, oral).

- La caseta la podemos gastar si quieres (Inf. 24, oral). 
Objetos e instituciones de la vida diaria se emplean también en italiano debido a la alta frecuencia de uso en este idioma y la mayor capacidad de comprensión en general, por parte de otros grupos sociales y lingüísticos:

- Luego tengo que comprar la cartulina y después ir a la Posta. (Inf. 18, oral).

Otros términos que se asemejan a los españoles se encuentran en italiano por la posibie creencia de que en ambas lenguas coinciden, el caso de EVASOS, se ve favorecido por la existencia de EVASIÓN en español de la misma raíz:

- Encima el techo el detectiv Colombo acaba de observar una pelea entre dos evasos. (Inf. 23, escrito).

\subsection{Cambio de código}

Se incluyen aquí los casos en que el cambio de lengua se produce de una frase o expresión a la siguiente y no la sola inclusión de un término de otro idioma. Los encuestados parecen usar el cambio de código como un recurso para codificar citas que aparecen en el discurso, enfatizar, acotar, añadir emoción o aumentar el interés de la comunicación:

El cambio de un idioma a otro no siempre es por falta de recursos lingǘsticos, sino que a veces sirve como un marcador para mostrar solidaridad étnica o para enfatizar, claborar una idea y comunicar expresiones idiomáticas o dirigirse a una persona determinada. (Ramírez, 1992: 104).

Todas las ocurrencias han sido recogidas, naturalmente, en materiales orales, pucs se trata de recursos y posibilidades pragmáticas de la comunicación oral.

Se observa en los primeros ejemplos como los encuestados se sirven del cambio de código para enfatizar una parte del discurso. Se trata de un valor retórico que busca añadir un componente emocional a la comunicación:

- Yo no soy la típica que digo ah sólo quiero trabajar en esto y si no encuentro este trabajo no ++ nooo + yo quiero decir muchísimas cosas + quiero decir cualquier cosa soy abierta o estoy abierta ieh! [se ríe] soy abierta, estoy abierta para tantas cosas + ¿no sé cómo se dice? + quiero decir lo que sea ich nehme alles ++ cualquier cosa $++i c h$ nehme alles an ++ cualquier cosa la tomo no sé. (Inf. 13, oral). 
- Entonces cambias la frase y dices bueno la diré de otra manera ++ pero yo + ich bin mehr bewusst de lo que me pasa con esto + así soy así me tengo que aceptar. (Inf. 13, oral).

En el siguiente enunciado se trataría de una expresión estereotipada, cuya frecuencia de uso en alemán es elevada, pero además aparece en un momento en que el discurso cambia de la narración a una acotación personal:

- l¿De qué era el reportaje del periódico?] Del viaje ¿Cuál era? ich weiss nichl jah! Seychelles, las islas del océano Pací= + Índi= + Indischer Ozean alli todas esas islas xx maravillosas + eso entran ganas de ir allí. (Inf. II, oral)

Igualmente la expresión esterotipada o etiquetada se manifiesta en la lengua en que se realiza habitualmente. El informante está en la peluquería y habla acerca de una niña que se encuentra allí y sobre la que expresa una exclamación afectiva en alemán suizo:

- Yo no mo puedo mover porque si no me va a cortar el resto del pelo que tengo $++i$ ay! $i$ es isch Gott [ríe] ¿no Jlora cuando se despierta?. (Inf. 23, oral).

En el mismo sentido que los enunciados anteriores, se cambia el código lingüístico para hacer un inciso, un paréntesis en forma de pregunta que interrumpe la narración:

- Yo nunca me sentí realmente gallega + yo me siento más una mezcla + ¡ch! cómo decirte + España + ¿Wie sagt man vermittler? [...] vermittler $\mathrm{cn}$ el sentido de yo estoy aquí como española. (Inf. 10, oral)

Es también frecuente la codificación de citas en el idioma original, incluso de manera parcial y con traducción para enfatizar, como podemos observar a continuación:

- Hay muchos que se han crecido aquí + a lo mejor por el nombre ++ pero dicen «no, no de verdad» + dicen «no, no ich bin schweizer + yo soy suizo tongo pasaportc suizo». (Inf. 18, oral).

Siguiendo los ejemplos anteriores, la exclamación que interrumpe la narración se realiza con cambio de código para expresar un cambio del estilo narrativo a la exclamación personal en el relato: 
- [Cuenta la enfermedad de su padre] ¿Qué vas a hacer? Es ist alles menschlich + como se dice + es todo humano ++ esperemos que no + que pase bien la noche. (Inf. 18, oral).

La secuencia más interesante desde el punto de vista de la aternancia de códigos se produce en una conversación telefónica entre el informante y su madre (española de primera generación) que sucede durante la grabación. Se puede observar el uso de elementos estercotipados del alemán suizo en el saludo informal (HOI 'hola'), el marcador fático que regula el contacto (¿,ODER? '¿no?, ¿verdad?'), la expresión del desacuerdo (JA SICHER NICHT 'seguro que no'), de la conformidad con el interlocutor (MOLL 'sí, claro' —en alemán estándar doch, jawohl-); la despedida informal de origen italiano CHAO se emplea muy a menudo en el alemán suizo; por último para la Cormulación de la invitación a hablar el informante recurre al italiano (¿QUÉ COSA?):

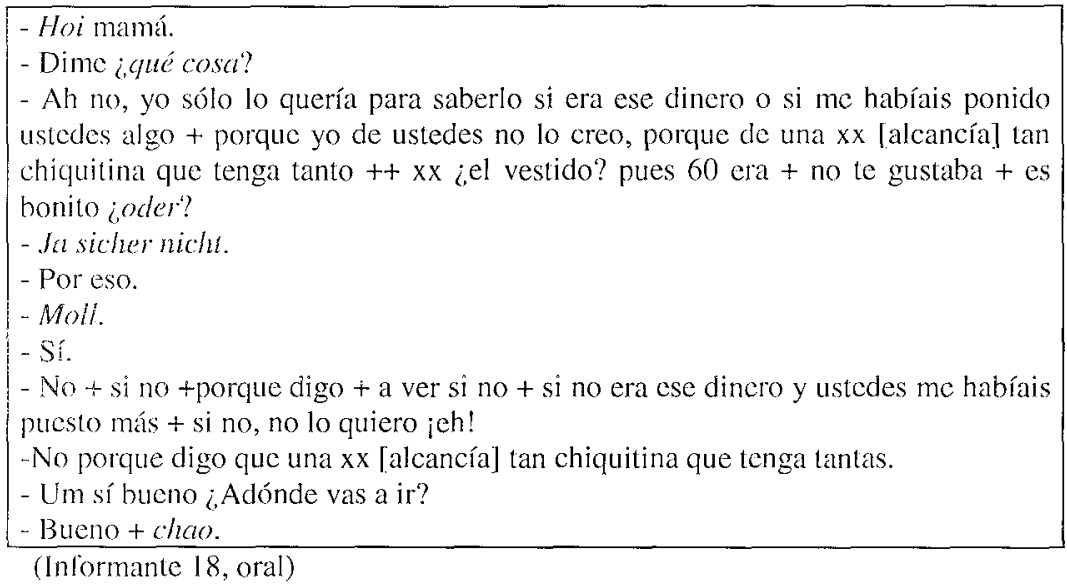

Se trata más de elementos con una alta frecuencia de uso cuyo valor expresivo y pragmático destacal sobre el informativo.

\subsection{Aduptación}

La adiaptación está condicionada por la cercanía fonética de significantes entre cl lérmino español y el alemán (o italiano). Es un procedimiento por el cual se asimilan aquellas voces que tengan en español una correspondencia fonética bastante aproximada por medio de algún tipo de transformación, con independencia 
del signilicado. La españolización se realiza a través de algunos de los sufijos españoles más productivos o de la eliminación de los elementos que vayan contra la estructura de la lengua:

KOMPLEX > COMPLEXO:

- Lucgo el francés + el francés me parece que es muy + aprenderlo es muy complexo+ sí + muy + tiene mucho que aprender. (Inf. 10, oral).

FOLKLORISTISCH 'folclórico' > FOLCLORÍSTICO:

- En el Centro Español + en donde daban clases de baile folclorístico español + ahí nos hemos conocido. (Inf. 23, oral).

Otros términos recogidos como observador activo en conversaciones con los in formantes son LUJURIOSO < LUXURIÖS 'lujoso' (que produce una sonrisa en hispanohablantes que no saben alemán porque lujurioso en español es 'unzüchtig, geil'), TEORÉTICO < THEORETISCH 'teórico', ABONAMENTO < ABONNEMENT 'abono, suscripción', FRISURA < FRISUR 'el peinado', INTERVISTA < INTERVIEW 'entrevista'.

La adaptación a las reglas morfológicas de formación del plural se realiza al aplicar la ecuación -EN > -Os; como en SERBEN > *SERBOS:

- [Mis amigos son] serbos, alemanes, italianos, franceses. (Inf. 1, oral).

Otro tanto ocurre con voces que en español son femeninas: REPARATUR 'reparación' > *REPARATURA

- Y quién me paga la reparatura. (Inf. 9, oral).

Puede suceder también que la forma sea calcada literalmente de otra lengua olvidando las reglas de construcción sintagmática del español, de esta manera MUTTERSPRACHE (o MADRELINGUA, en italiano) se adapta en esta forma al español, cuando lo correcto sería utilizar un sustantivo seguido de un adjetivo LENGUA MATERNA y no una expresión compuesta de dos sustantivos y en orden inverso al normal en español --en alemán, en cambio, es el orden obligatorio adjetivo + sustantivo-:

- La mayoría de madre lengua española no puede transmitir a sus hijos el catalán. (Inf. 1, escrita).

Otro verbo tomado del italiano es *APARTENECER que es el resultado de la adaptación al cspañol de APPARTENERE (reforzado por el francés APPARTENIR), al cual se le ha simplificado el grupo - PP- que no es admisible y se le ha añadido la terminación - CER de la palabra española, seguramente 
conocida por $\mathrm{cl}$ informante como competencia pasiva, como demuestra el hecho de la fluctuación de la segunda-A-:

- Pcro el alemán estándar les da la oportunidad de poder apartenecer a la comunidad internacional de habla alemana. (Inf. 1, escrito).

En español existe el sustantivo ELENCO 'catálogo, índice', pero se trata de una voz de escaso uso y restringida a registros cultos; en cambio en italiano se trata del término normal, por ejemplo, ELENCO TELEFONICO 'guía telefónica'; y por cste camino ha llegado hasta el informante que utiliza en varias ocasiones el verbo :ELENCAR, inexistente en español, en lugar de CLASIFICAR, CATALOGAR:

- Todo tipo de anotación y citación que no pertenezca a dicha obra será mencionada en el texto y elencada más precisamente a continuación de éste bajo un índice de citas. (Inf. 3, escrito).

La aparición de *EMPEÑATIVO se hace a partir del italiano IMPEGNATIVO 'comprometido, que exige un esfuerzo' favorecido por la existencia de EMPEÑO. El sulijo-IVO que «puede significar capacidad para lo significado por la base o inclinación a ello» (DRAE) es igualmente frecuente en español:

- Ya lo ha dejado porque también es un cargo + bastante empeñativo. (Inf. 11 , oral).

- No es un grupo empeñativo + en el sentido de que es un grupo que te da poco trabajo. (Inf: 13, oral).

El uso de *CONSEJAR está determinado por la existencia en italiano de CONSIGLIARE, a partir de la siguiente ecuación: si es CONSIGLIO igual a CONSEJO, CONSIGLIARE será igual a *CONSEJAR:

- Hasta los tres años me han consejado de hablarle el italiano con ella y me han + mi marido el italiano. (Inf. 23, oral).

- El vendedor de coches se acerca para consejar a Pedro. (Inl. 23, escrito).

Mención aparte merecen las voces tomadas de la terminología científica, en este caso lingüística. La adaptación al español por medio de sulijos suele ser el recurso más habitual. Esto es así por la facilidad que tienen los estudiantes universitarios entrevistados, gracias a su multilingüismo, para consultar diferentes fuentes en la lengua original. El término inglés usado en Pragmática IMPLICATURE ha sido adaptado por medio del sufijo -URA que se usa «para crear sustantivos que expresen la idea de acción» (Alvar Ezquerra, 1993: 52), pero que sobre todo es el que más se asemeja a la terminación inglesa de esta voz: 
- Este mecanismo de interpretación se llama implicatura convcrsacional. (Inl. 7, cscrito).

\subsection{Calco}

Se han recogido en los materiales estudiados ejemplos de germanismos o italianismos semánticos que mantienen inalterada la forma española:

Un calco semántico del alemán y del italiano está detrás de la fórmula MIRAR LA TELEVISIÓN (en el alemán de Suiza FERNSEH LUEGE, en italiano GUARDARE LA TELEVISIONE), pues en el español peninsular —el informante es originario de la Península - el verbo requerido para esta acción es VER a causa de que contiene el sema [+gozo] y expresa la idea de consumición (Matte I, 1992: 266) lirente a MIRAR:

- Yo miro muy poca tele, si miro, miro las noticias. (Inf. 10, oral).

El uso frecuente del verbo *EVOLUCIONARSE en lugar de DESARROLLARSE, como parece lógico en el siguiente enunciado, tiene su razón de ser en el hecho de que ambos, tanto EVOLUCIONAR como DESARROLLAR(SE), se corresponden con el verbo alemán SICH ENTWICKELN. Sin embargo el informante no distingue bien la diferencia semántica cntre cllos, y probablemente los sienta como sinónimos al coincidir en un único signilicante alemán la diferenciación semántica que el español expresa con dos significantes:

- Con la expansión esterior se evoluciona una expansión interior. (Inf. 2, escrito).

ESTUDIO 'carrera universitaria' toma este significado del término alemán STUDIUM. Está muy generalizado:

- Bucno yo empecé a estudiar aquí francés y después no me gustó el estudio, lo dejć. (Inf. 1, oral).

GIMNASIUM 'Instituto de enseñanza media' > GIMNASIO; en este caso se produce adcmás de un calco semántico del alemán que añade una nueva acepción a la palabra española, la adaptación fonética:

- Son años donde uno hace amistades más profundamente + yo picn $=+$ amistades más profundas +++ donde uno también se conoce jeh! $+o$ 
donde uno llega también a tener conversaciones donde son distintas a los años de gimnasio + de los años de bachiller o de COU o no sé. (Inf. 13, oral).

PROGRESIVO ha tomado el significado del término español PROGRESISTA, 'de actitud más avanzada e innovadora que los otros', por calco del alemán PROGRESSIV 'progresista':

- Ya muy pronto el dialecto castellano se diferenció de los romances vecinos por su carácter progresivo. (Inf. 7, escrito).

KONKURRENZ 'competencia' determina la adopción de este significado por parte de la voz española CONCURRENCIA "coincidencia en el tiempo o el espacio de personas o hechos'; favorecido por la existencia del italiano CONCORRENZA y del hrancés CONCURRENCE, ambos con el mismo significado que en alemán:

- Algunos no se llevan bien con la concurrencia. (Inf. 18, oral).

El término alemán STRASSE posee la doble significación 'calle' y 'carretera'. Con frecuencia se utiliza CALLE en español con el significado calcado de 'carretera':

- $\quad$ ¿ Pero no fuisteis a Lugano (desde Andermatt) por la autopista? ¡Hombre no! Claro que no + por la calle + la calle principal + porque si vas por la autopista habrá que poner un motor a la bici. (Inf. 24, oral).

En el siguiente enunciado el informante aplica de manera particular el signilicado de la partícula francesa MÊME, que tiene aquí el mismo valor que la alemana SOGAR, al español MISMO, cuando lo ideal hubiera sido emplear INCLUSO. Se encuentra esta transferencia tanto en textos escritos como en orales:

- O sea que muchos barrios, calles, tiendas y mismo familias apertenecen a una de las dos comunidades. (Inf. 1, escrito).

Otro calco semántico, esta vez de procedencia italiana y francesa, se encuentra en la utilización del verbo español EXPRIMIR 'sacar el jugo a una fruta' con el signilicado italiano y francés de 'expresar' en ESPRIMERE y EXPRIMER, respectivamente:

- Así pues, sólo el modo de exprimirse en el alemán estándar puede darnos informaciones sobre la posible posición y el entorno social del hablante. (Inf. 1, escrito). 
El calco del significado parcial en italiano de TANTO 'mucho' que el informante aplica a TANTO en español:

- No hay + no creo que haiga tantos campesinos. (Inf. 1, oral).

La aparición de PASAJE 'invitación a viajar con alguien en su coche' está tomada del italiano PASSAGGIO:

- A veces bajo en el hermano de alguien ++ sabes que vuelven en coche o que bajan en coche + entonces alguien te da un pasaje [...] que te dicen «tengo un sitio en el coche quieres venir». (Inf. 13, oral).

El informante 8 a la hora de explicar su trabajo ha de recurrir a un vocabulario más cspecílico y cs solamente entonces cuando encuentra dificultades. Recurre a COMUNIDAD calcando cl término italiano COMUNE 'ayuntamiento, municipio', pero no porque desconozca la voz AYUNTAMIENTO sino porque ignora que con esta palabra se designa en español la organización político-admistrativa local y por tanto no puede hacer las correspondencias administrativas entre Suiza y España:

- Trabajo en cantonal ¿no? y no tenemos clientes ni nada eso lo hacen las comunidades + la ciudad y las comunidades Horw + Littau todo eso. (Inf. 8 , oral)

Las expresiones italianas FARE UNA SORPRESA y SUONARE IL CAMPANELLO sirven de base a los calcos que a continuación se presentan y que sustituyen a DAR UNA SOPRESA y TOCAR EL TIMBRE. La seguridad de la comprensión del mensaje favorece la producción de este tipo de fenómenos:

- A la vecina, el marido de esta, le acaba de hacer una sorpresa. (Inf. 23, escrito).

- Y al sonar un vecino el timbre se muere del susto al abrirse la puerta. (Inf. 23 , escrito).

CARTULINA con el signilicado de 'tarjeta', calcado del italiano CARTOLINA:

- Luego tengo que comprar la cartulina y después ir a la Posta. (Inf. 18, oral). 


\subsection{Preferencias}

Bajo el tílulo preferencias recogemos aquellos casos de selección léxica en función de la existencia en la otra lengua de una forma correspondiente, rechazando otras más alejadas en la fonética.

El verbo FUNDAR se prefiere a FUNDAMENTAR porque existe en alemán FUNDIEREN y no una voz paralela a la segunda:

- Lo relatado se funda en informaciones propias. (Inf. 7, escrito).

De la misma manera se encuentra TEMPORADA PROVISIONAL en lugar de PERIODO DE PRUEBA, que sería más adecuado en el enunciado que a continuación se transcribe, debido a la influencia del término alemán PROVISORIUM:

- Todas las alumnas y los alumnos aceptados entrarán en una temiporada provisional que dura tres meses empezando al principio del año escolar. (Folleto informativo)

Otro caso lo encontramos en un enunciado anteriormente estudiado donde el informante elige *COMPLEXO influido por el alemán KOMPLEX, en vez de COMPLICADO O DIFÍCIL.

- Luego el francés + el francés me parece que es muy + aprenderlo es muy complexot sí + muy + tiene mucho que aprender. (Inf. 10, oral).

Lal expresión alemana DIE DEUTSCHE SPRACHE 'la lengua alemana' se siente como más culta, más adecuada a un registro más cuidado y no DAS DEUTSCHE 'cl alemán', de forma similar es frecuente encontrar LA LENGUA ESPAÑOLA o EL IDIOMA ESPAÑOL en lugar de EL ESPAÑOL cn los informantes con la intención de conseguir también en español ese registro cuidado, por ejemplo:

- Mi español es todavía el que traigo de España y no he aprendido más sino que me he olvidado de la lengua española. (Inf. 10, oral).

- Estuve siete meses en Ginebra para aprender el idioma francés. (Inf. 23, oral)

La elccción del término TRANSMITIR, en lugar de ENSEÑAR, está condicionada por el alemán VERMITTELN: 
- La mayoría de madre lengua española no puede transmitir a sus hijos el catalán. (Inf. 1, escrita).

\section{Desplazamientos ${ }^{2}$}

En ocasiones los informantes que desconocen o sólo tienen la competencia pasiva de algunos términos, no recurren a la transferencia de otro sistema lingüístico, sino que desplazan inconscientemente el significado que desean expresar a un significante equivocado. Esta imprecisión léxica es bastante frecuente cntre los españoles en Suiza, podría encuadrarse dentro de la tendencia general a la simplificación y la pérdida de algunas distinciones. El fenómeno, que hemos llamado «desplazamientos» por la movilidad de los elementos, está condicionado por la contiguiidad de significantes, de significados o de ambos a la vez.

\subsection{Contigiiidad de significantes}

En primer iugar presentamos algunos casos de desplazamiento de significados a significantes equivocados. La cercanía fonética entre el término usado por el informante y cl real en la lengua estándar está en la base de este fenómeno. Se produce por la falta de uso y una competencia en esencia pasiva de estas formas:

Indispensable por IMPENSABLE:

- A ese hay que darle sobresaliente porque es el hijo de tal y tal militar + porque es hijo de tal y tal porque es eso ++ eso aquí en Suiza es indispensable ¿sabes? + no sé, aquí no te lo puedes imaginar. (Inf. 3, oral).

Intercaladamente por ALTERNATIVAMENTE:

- [Viajamos] intercaladamente una vezél + una vez yo. (Inf. 7, oral).

Llamar la intención por LLAMAR LA ATENCIÓN:

- No me llama la intención + estoy como fuera de todas las conversaciones. (Inf. 7, oral).

\footnotetext{
${ }^{2}$ Se ha elegido este término para cxpresar el carácter dinámico del fenómeno. En inglés shifi, en alemán Verschiebung.
} 
Parece que esta última estructura es frecuente causa de duda o error. En más de una ocasión, se ha podido comprobar una cierta prudencia en los hablantes a la hora de emplearla:

- No sé no me llama la +++ no me interesa. (Observación participativa en un locutor de $1^{a}$ generación)

\section{Plantar por PLANTEAR:}

- Programando más o menos qué clase de vida quieres llevar allá, pues yo me lo podría plantar en serio. (Inf. 10, oral).

Plantear por PLANEAR:

- Tienen todo planteado. (Inf. 17, oral).

- Verano por VERANEO:

- Lo que yo me acuerdo del pueblo es que cuando íbamos de verano pues se llenaba el pueblo de ++ de los que salieron + o cómo se dice de los que + emigraron (Inf. 23, oral).

Cotidicino por DIARIO. En este caso concreto no se trata tanto de un error en la inlormación como de una selección poco habitual para el contexto en que se produce la comunicación. Puede ser también importante la influencia de la voz francesa QUOTIDIEN 'diario':

- Ya + pero en el tren ¿qué hago en el tren? pues leo el periódico cotidiano. (Inf. 19, oral)

\section{Atribución por DISTRIBUCION:}

- En España existen cuatro lenguas con la siguiente atribución geográlica. (Inf. 2, escrito).

Plegado por PLAGADO:

- Los escritores utilizaron la lengua de su entorno social, un dialecto local plegado de castellanismos. (Inf. 3, escrito).

Al respeto de por RESPECTO A / DE:

- La lengua de los visigodos y la lengua árabe también son superestratos al respeto de la lengua de los romanos. [...] También el latín es un superestrato al respeto del visigodo y el árabe. (Inf. 4, escrito). 


\section{Piojos por PIJOS:}

- Me gustó [Sierra Nevada] pero había muchos piojos. (Observación participativa).

En algún caso, por tratarse de realizaciones orales los informantes han podido corregir y encontrar el término adecuado:

- Hay que tener cara dura para dejar que la gente haga juerga, eh huelga, cstando a semana de jugar los mundiales. (Inf. 10, oral).

- $\quad$ Hablar andaluz] es cool + digamos es chachi + tiene palabras que + muy divertidas muy originarias + originales. (Inf. 11, oral).

En otros la rectificación los lleva a caer en la imprecisión:

- Cuando + escribo un texto tengo faltas de alemán ++ de declinaciones ++ más que + por los artículos por ejemplo no siempre sé qué artículo son con + quiero decir los dices por + que $a=$ los dices acaso $++[$ ríe] los dices acaso + así de casua = no sé cómo decirlo + lo dices sí acaso [ríe] ¿cómo se dice? (Inf. 13, oral).

- No me pongáis en una clase intermedia + intermediaria + prefiero que me pongáis en una clase + en una clase más alta. (Inf. 14, oral).

La confusión de intermediaria con INTEMEDIA se produce probablemente porque al informante le parece más lógico este término como componente de la seric: primaria, secundaria; y confirmada esta confusión por la existencia de INTERMÉDIAIRE en francés.

\subsection{Contigiiidad de significados}

La elección del significante en función del contexto no siempre se hace de mancra accrtada. Con relativa frecuencia palabras de un mismo campo semántico se usan indistintamente sin conservar la diferencia semántica entre los términos, eliminando las distinciones. De nuevo una simplificación en el vocabulario como nota característica del contacto de lenguas.

Miembros por SOCIOS, favorecido por la inexistencia de distinción en alemán y rrancés donde 'socio' y 'miembro' corresponden al término alemán MITGLIEDER y en francés MEMBRE, directamente emparentado con la palabra española: 
- No encontramos ni el sitio primero + después eran [los asientos] creo de ++ de unos ++ miembros. (Inf. I, oral).

Vivencia por FORMA DE VIVIR:

- La vivencia, la manera como la gente se trata entre sí. (Inf. 7, oral).

- Suspender por APROBAR:

- ¡Um! + me quedć suspendida + suficiente, suficiente, sí está bien, no sé + bueno. (Inf. 18, oral).

Letra por ESCRITURA:

- Claro está que de esa manera no se han adquerido conocimientos de la letra. (Inf. 1, escrito).

\section{Indígenas por AUTÓCTONAS:}

- Al lado de las cuatro lenguas indígenas encontramos otros idiomas hablados más o menos permanentemente por grupos de extranjeros. [se refiere a Suiza] (Inf. 1, escrito).

Discursos por DEBATES, DISCUSIONES:

- El gobierno le concede el Estatuto de Autonomía después de grandes discursos. (Inf. 2, escrito).

Inscripciones por RÓTULOS, CARTELES:

- En Cataluña la enseñanza básica es en catalán, inscripciones, etc. están en catalán. (Inf. 5, escrito).

Otro caso de simplificación lo encontramos en el uso de ESCUELA por UNIVERSIDAD, donde entendemos que el informante se refiere a cualquier nivel educativo con ESCUELA:

- Se trata de una chica que está también haciendo unos trabajos para la escuelc y ella trabaja por el cine, me parece. (Inf. 12, oral).

La observación participativa ha permitido descubrir algún otro ejemplo significativo como la confusión entre ENSEÑAR y APRENDER, que se reducen a APRENDER, de este modo es posible escuchar entre jóvenes españoles en Suiza «ni amigo me ha aprendido a usar su ordenador». Se trata de un fenómeno frecuente en italiano subestándar con el uso de IMPARARE como 'aprender' y 
'enseñar' (»lui mi ha imparato questa lingua» 'me ha enseñado este idioma', pero «io (mi) ho imparato questa lingua» 'he aprendido este idioma'), en alemán suizo LEERE también 'aprender' y 'enseñar' , y en francés normalmente APPRENDRE se usa con cl significado tanto de 'aprender' como de 'enseñar', reservándose ENSEIGNER para usos exclusivamente formales. Así pues las tres lenguas prescntan una característica similar que se transmite a los españoles multilingües de Suiza, y con toda probabilidad por este orden de intensidad italiano, alemán suizo y francés (que como lengua románica que se aprende en la escuela viene a confirmar algunos fenómenos) $)^{3}$.

\subsection{Contigiiidad de significado y significante}

El fenómeno de contigüidad de significantes se puede interpretar como ligado a un déficí de aprendizaje o a una insuficiente consolidación de determinadas estructuras del sistema. El de contigüidad de significados comparte la misma causa pero también aparecen ya algunos casos de pérdida de las distinciones. En cambio, cl fenómeno de simplifícación basado en la reducción de palabras de un mismo campo semántico y con cuerpo fonético similar nos remite de una manera evidente y general a un debilitamiento claro de las distinciones:

Trayecto por TRAYECTORIA, que se emplea en sentido figurado:

- [De Mozart me interesa] su vida su trayecto como ha conseguido de hacerse un puesto ino?. (Inf. l, oral).

Viudez, que hace relerencia al estado, por VIUDEDAD, que se usa para denominar el tipo de pensión que recibe una persona viuda:

- A mi madre [...] no le dan ese dinero, le darían una pensión de viudez. (Inf. 11, oral).

Encontrar a alguien por ENCONTRARSE CON ALGUIEN:

- Esta semana me resulta muy difícil encontrarte. (Inf. 16, oral).

Relajante por RELAJADO:

- No sé cómo expresarme + que lo cojo todo un poco más relajante lal vcz aunque no siempre. (Inf. 19, oral).

\footnotetext{
${ }^{3}$ Mi gratilud a Stephan Schmid por su colaboración en la aclaración de este punto.
} 


\section{Primordial por PRINCIPAL:}

- El castellano termina de convertirse en lengua primordial gracias a su prestigio. (Inf. 2, escrito).

Anciana por ANTIGUA. La voz anciana posee el sema [+ persona] frente a ANTIGUA. En francés, en cambio, la voz ANCIENNE sería la correcta en este caso, por lo que no se descarta un calco semántico:

- El vasco es la lengua más anciana al oeste de Europa. (Inf. 2, escrito).

Dialectológicos por DIALECTALES, similar a la pérdida de distinción en que caen determinados periodistas en el uso de climatológico en lugar de climático:

- El latín del Norte era un latín menos culto, la población que la [lo] importó cra soldadesca y campesina, y además con rasgos dialectológicos de ltalia. (Inf. 6, escrito).

Localistas por LOCALES. En este caso no se trata de una actitud a favor de los aspectos locales, sino de aspectos propios de un lugar:

- El castellano [...] gracias al contacto de otras lenguas se tuvo que complejizar y desprenderse de aspectos localistas. (Inf. 6, escrito).

Reinado 'espacio de tiempo en que gobierna un rey' (DRAE) por REINO 'territorio gobernado por un rey':

- A partir de ese momento se puede hablar de una unidad entre los reinados que expulsaron a los árabes. (Inf. 1, escrito).

- Cuando en 1035 se constituyó en reinado se avanzó más rápido en la Reconquista. (Inf., 6, escrito).

Fortificar por FORTALECER, REFORZAR:

- Los esfuerzos por parte de las entidades competentes para fortificar la posición de la lengua local. (Inf. 8, escrito).

En el siguiente caso la cercanía de significantes ha confundido al informante produciendo un enunciado incorrecto desde el punto de vista semántico:

- Con la Reconquista el castellano reconquista terreno. (Inl. 2, escrito). 
Por último encontramos un caso aparte basado en la confusión o fantasía del informante:

- Al Noroeste de Castilla, el leonés hace frontera con el gallego, mientras que hacia Cataluña es el aragonés el que funda como zona fronteriza. (Inf. 2, escrito).

\section{Creatividad}

En general, los estudios que tratan el contacto de lenguas se han interesado de manera especial por las cuestiones de cambio de código o los préstamos léxicos, pero en el material que hemos manejado para este análisis la creatividad, la utilización de neologismos generados de manera individual, supone una parte importante de los resultados obtenidos. Por esta razón merecen un apartado específico estas creaciones que no existen en el español de los hablantes monolingües, pero que podrían existir. La capacidad de los hablantes bilinguies o multilinguies para desarrollar muchas de las posibilidades que las lenguas poseen ya ha sido analizada por investigadores interesados en el desarrollo del bilingüismo como Hoffman al indagar acerca de la adquisición del bilingüismo en niños:

«Là posible posesión de un léxico más rico en el caso del monolingüe quizá queda compensada por la más amplia gama de recursos verbales del bilingüe. [...] En términos de competencia comunicativa, se puede estimar que el bilingüe es tan elicientc como el monolingüe, ya que tiene a su disposición ciertas estrategias que le permiten hacer amplio uso de los recursos de sus dos lenguas, esto puede incluso enriquecer su producción lingüística, en especial cuando habla con otros bilingües, aunque también puede resultar en fenómenos de interferencia, lo que a su vez es posible que constituya un cierto estorbo para la comunicación, particularmente cuando $\mathrm{cl}$ interlocutor es monolingüe». (1989: 39)

El porqué de esta realidad se halla en la necesidad de usar determinados conceptos relacionados con usos cultos de la lengua. El desconocimiento de las formas en español estándar lleva a la creación por los medios de formación de palabras, con toda probabilidad de una manera inconsciente. Se trata de construir un enunciado que pueda ser entendido, a pesar de no ser correcto en la lengua normativa (haya o no consciencia de irregularidad). Factores importantes en este fenómeno suclen ser el olvido o el desconocimiento de estos términos en español estándar. La urgencia o la necesidad inmediata de usar estos conceptos favorece su manilestación. Diecisiete de estos neologismos han sido recogidos en materiales escritos y seis en orales. 
Alguna de estas nuevas creaciones entra dentro de la creciente moda de alargar con sulijos palabras ya existentes. Esta tendencia es muy acusada en el lenguaje polílico y periodístico, por lo que cabe pensar que se trata de imitar el lenguajc escrito de la prensa o la televisión (la mayoría afirma que el programa de televisión española que más le interesa es el telediario). Además la prensa y la televisión son algunos de los pocos medios de corrección culta que poseen y los toman como modelos de «prestigio».

Todos estos nuevos términos se generan con los mecanismos de formación de palabras del español, es decir, son posibilidades que la lengua general no ha tomado pero que son en potencia posibles. La mayoría de los neologismos recogidos son utilizados con la pretensión de dotar al texto de unos registros léxicos de carácter culto. El método más común es la derivación con sufijos conocidos, y en muy menor medida la prefijación.

En cuanto a los sustantivos, los principales recursos son:

El sufijo-DAD para producir sustantivos abstractos que designan la cualidad:

- Tampoco supo hacer frente a la tendencia de centrifugacidad de las variedades dialectotópicas. (Inf. 6, escrito).

- Por todos lados hay que mencionar la bilingüedad regional. (Inf. 22, escrito).

Ei sufijo -CIÓN «de sustantivos verbales que significa acción y efecto» (DRAE):

- La cerración. (Inf. 1, escrito).

- La incrementación y extensión de la producción editorial. (Inf. 13, escrito).

- El turismo, junto con una cierta reactivización de la actividad pesquera, son los causantes de la actual conformación de este barrio del puerto. (Inf. 13, escrito).

INCREMENTACIÓN y REACTIVIZACIÓN esconden la misma motivación que lleva a ciertos hablantes a preferir «peligrosidad» o «intencionalidad» en vez de «peligro» o «intención». Moda de alargar palabras muy relacionada con los medios de comunicación y la pedantería que se ha instalado en ciertos estilos de decir como la política o las ciencias humanas.

El sulijo -ENCIA «Sufijo de sustantivos femeninos abstractos, de significado muy variado, determinado por la base derivativa» (DRAE), de gran productividad (exigir $\rightarrow$ exigencia). En el caso de PROVENIENCIA puede ser que la voz francesa provenance favorezca su creación, debido a la alta competencia del informante $1 \mathrm{cn}$ esta lengua; el informante 2 deriva la voz directamente del verbo PROVENIR: 
- Emigración de Galicia. La garantía de sobrevivencia de esta lengua no es dada. (Inf. 22, cscrito).

- Así pues la tripulación de los barcos es mayoritariamente de proveniencia andaluza. (Inf. 1, escrita).

- El vasco [...] es un resto de una cultura pastoril europea de la región pirinaica. El problema de la proveniencia del vasco no ha sido resuelto todavía. (Inf. 2, escrita).

La clección de *DESCRECIMIENTO reside en la transparencia respecto a CRECIMIENTO, frente a RETROCESO, la forma habitual para este caso. Es uno de los pocos ejemplos de prefijación que se ha encontrado:

- Desde los años 50 se ve sometida a un descrecimiento vertiginoso. (Inf. 1, cscrito).

El sufïjo -ERÍA «de sustantivos no heredados del latin, que suele significar pluralidad o colectividad» (DRAE), sirve para construir la voz LOCERÍA 'conjunto de losas o losetas para revestir suelos', y que ya existe con el significado de 'fábrica de loza' (ver DRAE). Se prefiere una palabra derivada de LOSA en lugar de la tradicional SOLERÍA. La / $\theta /$ se explica por la variedad diatópica de los padres de este informante, procedentes de zona ceceante:

- Después tuvieron que estar buscando un local nuevo + que + y después el local que que estaba bastante prácticamente en ruinas + y tuvieron que pintarlo ponerle la locería las instalaciones sanitarias fontanería todo lo pusieron ellos por su cuenta por $=+$ la car $=$ carpintería todo el trabajo de albañi= de albañil y todo lo hicieron ellos por su cuenta para ahorrar dinero también. (Inf. 11, oral)

Para el significado 'decadencia' el informante 16 procede a la derivación del sustantivo verbal *DECLINE a partir de DECLINAR por medio de -E «sufijo de sustantivos verbales que significa acción y efecto» (DRAE), ya ignorando la existencia de DECLIVE ya confundiéndolo con este término, que es la voz recogida en el Diccionario Académico. A pesar de todo, la forma *DECLINE es perfectamente posible dentro del sistema del español:

- Ahora he comprado dos libros suyos - uno sobre el decline del imperio español y otro sobre el Conde-Duque de Olivares - para formarme un poco. (Inf. 16, escrito) 
El gentilicio de los habitantes de Salamanca es SALMANTINO, pero el informante lo desconoce, por lo que recurre a una formación analógica con otro gentilicio que sí conoce como es granadino (tiene una casa de vacaciones en esta provincia). Así pues, el procedimiento consiste en añadir el sufijo conocido - INO a la raíz del sustantivo:

- También puede ser de mi padre él es salamanquino y es muy tranquilo. (Inf. 19, oral).

Los adjetivos producto de creación que hemos recogido en los materiales analizados son los siguientes:

En primer lugar el adjetivo *PARAÍSICO ha sido formado a partir del sustantivo PARAÍSO con el sufijo -ICO «sufijo de adjetivos que indica relación con la basc derivativa» (DRAE). El informante desconoce que el adjetivo relacionado con PARAÍSO en la lengua estándar es PARADISIACO (es incluso posible que se haya formulado el siguiente razonamiento: si theoretisch es teórico y no teorético, paradiesisch es paraísico y no paradisiaco). Por otra parte, puede tratarsc simplemente de la adaptación del sufijo alemán -ISCH > -ico, como ocurre también en *TEORÉTICO < THEORETISCH. O la interacción de ambos fenómenos a la vez:

- Pues paraísico + es muy idílico y tranquilidad como te lo imaginas. (Inf. 11 , oral).

La formación *RADICALIZANTE en lugar de RADICAL, se debe, como ya se ha explicado para otras formaciones, a la creciente moda de alargar las palabras para conseguir una mayor expresividad y un mayor énfasis en su dicción. En este sentido el informante se deja llevar en una realización escrita por esta moda:

- Primeras apariciones de organizaciones nacionalistas radicalizantes. (Inf. 3 , escrito).

El adjetivo SOBREINDIVIDUAL se ha creado con el prefijo SOBREignorando que en estos casos se suele emplear SUPRA- como elemento compositivo para neologismos de carácter culto en cualquier disciplina científica, como es elcaso del ejemplo, en la Lingüística:

- El semema hay que entenderlo como una regla sobreindividual y sociocomunicativa que ha resultado de la comunicación. (Inf. 2, escrito).

Los verbos de creación recogidos son los que siguen: 
El primer caso de neologismo verbal que encontramos se refiere a un signilicante que el español estándar no posee, se trata del verbo que, en potencia, expresaría la acción de la base léxica de DICTADOR, derivado de DICTADURA. Es frecuente la formación de verbos de la primera conjugación derivados de sustantivos (Alvar Ezquerra, 1983: 60). La homografía con DICTAR 'decir un dictado' es casual.

- En 1923 José Primo de Rivera dicta en España. (Inf. 2, escrito).

De adjelivos derivan algunos verbos formados con el sufijo culto -IZAR, «verbos que denotan una acción cuyo resultado implica el significado del sustantivo o del adjetivo básicos» (DRAE). Este término ya fue creado por el romanista de la Universidad de Zúrich Georg Bossong, el cual es, a su vez, profesor de una parte de los informantes entrevistados para este trabajo:

- El castellano [...] gracias al contacto de otras ienguas se tuvo que complejizar y desprenderse de aspectos localistas. (Inf. 6, escrito).

El verho *INVASAR sería el hipotético verbo derivado del sustantivo INVASIÓN:

- Cuando los árabes invasaron en 711 la Península, llegaron a conquistar 3/4 de la Península. (Inf. 20, escrito).

*EXPARSIR es cl resultado de la fusión entre el sustantivo EXPANSIÓN + el vcrbo ESPARCIR:

- En el norte de la Península se formaron entonces núcleos lingǘísticos que a lo largo del tiempo se fueron exparsiendo por la Península. (Inf. 20, cscrito).

El verbo *INTERVIUBAR está formado a partir del sustantivo INTERVIÚ, con epéntesis de -B- para facilitar la pronunciación. Es bastante frecuente la formación de verbos en -AR con el sentido de 'acción' a partir de sustantivos:

- Que me está ahora interviubando! (Inf. 14, oral).

En general, la conjugación más productiva a la hora de crear neologismos suele ser la primera, cn -AR, por esto no es de extrañar que la confusión o la imprecisión con un verbo poco frecuente, o característico de estilos escritos y cuidados origine un cambio inconsciente de paradigma verbal. Es lo que ocurre con *CONCERNAR en lugar del estándar CONCERNIR 'atañer, afectar, interesar' (DRAE): 
- Si acaso algunas de las críticas concernaban el hecho de que C. no es de lengua materna española me parecería mas que ridículo. (Inf. 11, escrito).

La eliminación de elementos protéticos en los verbos *PASIONAR y *FLOJAR probablemente se deba a que el prefijo A- de las formas estándar respectivas APASIONAR y AFLOJAR carece de significación precisa. Por lo tanto para esto hablantes es un elemento irrelevante a la hora de derivar. Al contrario que en *CONSEJAR, ya analizado como adaptación del italiano CONSIGLIARE, la forma *PASIONAR no la podemos suponer como influencia italiana porque en este idioma se dice APASSIONARE, en cambio sí podemos pensar en que la forma francesa PASSIONER pueda confirmar la ausencia de la A-; respecto a *FLOJAR no hay duda, pues los correspondientes en italiano y francés están alejados fonéticamente. Para terminar con la cuestión de la eliminación de elementos protéticos señalaremos que las tres formas que carecen de este prefijo sin significación están empleadas por tres informantes diferentes, to que nos hace pensar en una regla de formación de palabras que elimina todos aquellos elementos que no aporten una carga significativa a la nueva palabra:

- Bueno el fútbol como que no me pasiona. (Inf. 5, oral).

- Te viene a casa y $++y+$ la cosa está muy + muy tensa y + y eso yo siempre procuro + flojar todo + todo el ambiente un poco. (Inf. 15, oral).

*RESPUESTO se ha formado como participio pasado irregular de RESPONDER por analogía con PONER $\rightarrow$ PUESTO, confirmado por la existencia de RESPUESTA, aunque se trate de un sustantivo la analogía ha funcionado (existe el arcaísmo RESPUESTO, -TA, en español pero el escaso uso hace poco probable su conocimiento por parte del informante):

- Perdona por no haber respuesto antes. (Inf. 16, escrito).

Sobre la base de CORRUPCIÓN se ha creado el verbo *CORRUMPIR, ignorando la existencia de CORROMPER:

[El dinero] da buenos resultados para adquirir algo, chantajear a algien, para corrumpir y todas esas cosas. (Inf.16, escrito).

Sustantivos:

\begin{tabular}{lll}
\hline BASE & CREACIÓN & ESTÁNDAR \\
\hline centrífuga & centrifugacidad & tendencia centrífuga \\
\hline Bilingüe & bilingiiedad & situación de bilingüismo \\
\hline
\end{tabular}




\begin{tabular}{lll}
\hline Cerrar & cerración & cerrazón \\
\hline Incrementar & incrementación & incremento \\
\hline Reactivar & reactivización & reactivación \\
\hline Sobrevivir & sobrevivencia & supervivencia \\
\hline provenir & proveniencia & procedencia \\
\hline crecimicnto & descrecimiento & retroceso \\
\hline Loza & loceria & solería \\
\hline declinar & decline & declive, decadencia \\
\hline Salamanca & salamanquino & salmantino \\
\hline
\end{tabular}

Adjetivos:

\begin{tabular}{lll}
\hline BASE & CREACIÓN & ESTÁNDAR \\
\hline Paraíso & paraísico & paradisiaco \\
\hline Radical & radicalizante & radical \\
\hline individual & sobreindividual & supraindividual \\
\hline
\end{tabular}

Verbos:

\begin{tabular}{lll}
\hline BASE & CREACIÓN & ESTÁNDAR \\
\hline Dictadura & dictar & $\begin{array}{l}\text { gobernar de forma } \\
\text { dictatorial }\end{array}$ \\
\hline Complejo & complejizar & complicar \\
\hline invasión & invasar & invadir \\
\hline $\begin{array}{l}\text { esparcir } \\
\text { expansión }\end{array}$ & exparsir & expandir \\
\hline interviú & interwiubar & entrevistar \\
\hline concernir & concernar & concernir \\
\hline pasión & pasionar & apasionar \\
\hline flojo & flojar & aflojar \\
\hline respuesta & respuesto (respuestar) & respondido (responder) \\
\hline corrupción & corrumpir & corromper \\
\hline
\end{tabular}

\section{Conclusiones}

La competencia en la propia lengua debe ser entendida como el resultado de los factores que confluyen en los hablantes, esto es, lengua de inmigrantes en una sociedala ajena al español, instrucción mínima o nula en la lengua materna, ausencia de contextos adecuados para desarrollar la calidad y cantidad de su uso, 
falta de modelos claros de corrección en muchos casos, etcétera. Sin embargo, la lengua conserva sus funciones y los hablantes dominan las reglas suficientes como para afirmar que se comunican en español. Claro está que su sistema lingüístico se ve afectado por circunstancias que no suceden en monolingües habituales «normales», pero si miramos un poco más allá nos podremos fijar en que sus características podrían ser paralelas a las de las diferentes variedades del español ${ }^{\circ} \mathrm{O}$ cs que éstas no poseen ciertas divergencias frente al núcleo común de la lengua general o estándar? ${ }^{4}$

Las características del léxico de los hispanohablantes de segunda generación en Suiza se pueden clasificar en tres grupos diferentes: el préstamo o transferencia de elementos de otra lenguá, los desplazamientos de significados o significantes en el uso de términos españoles y, por último, la creación de neologismos.

Todas estas características están estrechamente relacionadas con la situación de polimorlïsmo lingüístico y contacto de lenguas que viven estos hablantes. La aparición de soluciones distintas a las normales en la lengua estándar es, sencillamente, la consecuencia normal del manejo, más o menos constante, de dos o más códigos lingüísticos. Estas especiales circunstancias en que se desarrolla su práctica lingüística ha modificado la que en teoría hubiera sido su evolución lingüística natural, en algunas ocasiones para crear algo nuevo ajeno al sistema estándar.

La imprecisión en el manejo del vocabulario y la pérdida de distinciones (la mayoría de los desplazamientos por contigüidad) están motivadas por las condiciones en que se desarrolla su práctica lingüística. Su necesidad comunicativa cn español no va más allá de estilos familiares o coloquiales, y cuando -como ocurre con alumnos universitarios de español- se necesita una elaboración más formal o culta del sistema recurren a los registros aprendidos o caen en las divergencias que aquí comentamos.

La creación de neologismos, o mejor, el uso de los procedimientos de creación de palabras como la derivación, está determinado por el alivio que supone a la hora de recordar todo el caudal léxico. La mayoría de los neologismos pretenden dar un carácter culto a la comunicación, pero estos usos no son frecuentes para los hispanohablantes en Suiza por lo que mantener en su conjunto léxico estos lérminos se hace difícil. La eliminación de elementos poco relevantes en el campo semántico (por ejemplo en *FLOJAR o *PASIONAR) tiene también como resultado la creación de términos inexistentes en el sistema general del español.

En resumen, frente a los procesos de simplificación o pérdida, ya sea del léxico o de las distinciones semánticas, aparecen también formaciones originales producto

\footnotetext{
${ }^{4}$ La idea de considerar estas características léxicas (y lingüísticas) como equivalentes a las divergencias dialcetales de cualquicr otra variedad de español ha sido ya apuntada por Roberto Fernández (1987).
} 
de las normas de producción de neologismos del sistema y se hace en lugar de acudir a otro código linguístico. Por una parte se debilita el sistema, pero por otra cs el propio sistema el que dota de los recursos productores de nuevas posibilidades o soluciones.

Los hispanohablantes de la segunda generación en Suiza usan los recursos que cl mancjo de dilerentes sistemas pone a su disposición. Esperar un código más convergenıe con el estándar es desconocer la realidad de estos hablantes, pues ellos comunican lo que desean, se hacen comprender en español por los que forman parte de su red social, y en ésta sus características son absolutamente normales. El idioma es un instrumento de comunicación, estos hablantes se comunican en un sistema lingüístico con unas características muy particulares y diferentes al concepto que comúnmente se encuentra en las gramáticas sobre el uso de una lengua normativa, pero es que de no ser así su español moriría.

\section{Referencias bibliográficas:}

Alvar Ezqucra, Manuei (1993): La formación de palabras en español. Madrid: ArcoLibros.

Bácz de Aguilar González, Francisco (1997): La formación de identidad en la metrópoli. El conflicto linguiístico de los emigrantes castellanohablantes en Barcelona. Málaga: Universidad.

Berruto, Gactano (1984): «Appunti sull'italiano elvetico», Studi Linguistici Italiani, 10, págs. 76-108.

Bcruto, Gactano (1991): «Fremdarbeiteritalienisch: Fenomeni di pidginizzazione dell'italiano nella Svizzera tedesca», Rivista di Linguistica, 3/2, págs. 333-367.

Bossong, Georg (1987): «Sprachmischung und Sprachausbau im Judenspanischen», Iberoromania, 25, págs. 1-22.

Bossong, Gcorg (1994): «Sprache und regionale Identität». En Bossong, Georg et al. (eds.): Westeuropäische Regionen und ihre Identität. Beiträge aus interdisziplinärer Sicht. Mannheim: Palatium Verlag, págs. 46-61.

Bossong, Georg (1995): «Von der Dissoziation zur Integration, oder: weshalb «normalisiert» man Minderheitensprachen?». En Kattenbusch, Dieter (ed.): Minderheiten in der Romania. Wilhelmsfeld: Egert Verlag, págs. 33-44.

Bossong, Georg (1997): «Sprache und Identität in der hispanischen Welt». En Mocllcken, Wolfgang W. y Weber, Peter J. (edts.) Neue Forschungsarbaeiten zur Kontaktlinguistik. Bonn: Dümmler, págs. 65-80.

Fernández, Roberto G. (1987): «¿Modalidades léxicas del español de los Estados Unidos?», Actas del I Congreso Internacional sobre el español de América. Academia pucrtorriqueña de la lengua española, págs. 529-532. 
Franceschini, Rita; Müller, Myriam y Schmid, Stephan (1984): «Comportamento linguistico e competenza dell' italiano in inmigranti di seconda generacione: un indagine a Zurigo", Rivista Italiana di Dialettologia, VIII, págs. 41-72.

Hoffmann, Charlotte (1989): «Modelos de adquisición del bilingüismo infantil», Actas del VI Congreso de Lingiiística Aplicada: «Adquisición de lenguas: Teoría y aplicaciones». Santander, Asociación Española de Lingüística Aplicada, págs. 17-41.

López de Abiada, José Manuel y López-Bernasocchi, Augusta (edt.) (1982): Emigración, bilingiiismo, escolarización e inserción social: En torno a la segunda generación. Bellinzona: Edizioni Casagrande.

Lüdi, Georges (1998): «La lengua española en Suiza. Aspectos demolingüísticos y sociolingüísticos»m Estudios de Linguïistica y Filología Españolas. Homenaje a Germán Colón. Madrid: Gredos, págs. 283-300.

Matte Bon, Francisco (1992): Gramática comunicativa del español. Tomo I: De la lengua a la idea. Tomo II: De la idea a la lengua. Madrid: Difusión.

Ramírez, Arnulfo G. (1990): «Sociolingüística de la comunicación: Español e inglés en contacto en los Estados Unidos», Lingüística Española Actual, 12, págs. 257-273.

Ramírcz, Arnulfo G. (1992): El español de los Estados Unidos: El lenguaje de los hispanos. Madrid: Mapfre.

Sala, Marius $\left(1998^{2}\right)$ : Lenguas en contacto. Madrid: Gredos.

Schmid, Stephan (1986): «L'italiano lo so parlare bene». Aspetti dell'italiano parlato da immigrati di seconda generazione nella Svizzera tedesca. Trabajo de licenciatura inédito, Zurcí: Universidad.

Schmid, Stephan (1994): L'italiano degli spagnoli. Interlingue di immigranti nella Svizzera tedesca. Pavia: Francoangeli.

Silva-Corvalán, Carmen (1989): Sociolingüística. Teoría y análisis. Madrid: Alhambra-Universidad.

Silva-Corvalán, Caarmen (1992): «El español actual en Estados Unidos». En Historia y presente del español de América. Valladolid, Junta de Castilla y León, págs. 827-856.

Vaquero, María (1990): «Anglicismos en la prensa: Una cala en el lenguaje periodístico de San Juan», Lingiiística Española Actual, 12, págs. 275-287.

Vilar Sánchez, Karin (1995): Lengua y emigración. Estudio sociolingüistico de los procesos diglósicos entre los jóvenes españoles en Alemania. Granada: Universidad.

Zentella, Ana Celia (1987): «El habla de los niños bilingües del barrio de Nueva York», Actas del I Congreso Internacional sobre el español de América. Academia puertorriqueña de la lengua española, págs. 877-886. 